\title{
Impact of Coil Turns on Loss, Output power and Efficiency Performance of Flux-Pipe Resonant Coils.
}

\author{
Babatunde Olukotun \\ J.S. Partridge \\ Mechanical Engineering Department \\ University College London \\ London, United Kingdom
}

\author{
Richard W.G. Bucknall \\ Mechanical Engineering Department \\ University College London \\ London, United Kingdom
}

\begin{abstract}
This paper presents a finite element analysis of five different sizes of flux-pipe resonant coil design with a different number of coils turns but having the identical length of litz copper wire and aluminum shield. The analysis was undertaken to establish the impact of coil turns on the losses, magnetic flux distribution, power output, and power transfer efficiency of fluxpipe resonant coils. From the result presented, it was noted at a constant frequency, an increase in the excitation current causes a significant increase in the ohmic, core, and eddy current losses for each of the coil model designs.

Similarly, at constant excitation current, it was observed that the eddy current losses increase significantly with an increase in resonant frequency. In contrast, the ohmic and core losses are relatively constant over the range of resonant frequencies used in the analysis. It was also noted that term $k \sqrt{ } Q_{p s}$ (where $k$ is the coupling coefficient and $Q_{p s}$ is the product of the quality factor of the primary and secondary coils) has a significant influence on the input power, output power and coil-to-coil efficiency of a particular flux-pipe resonant coil design. Increasing the value of $k \sqrt{ } Q_{p s}$ increases the value of output power, input power and coilto-coil efficiency. Similarly, the lower the coupling coefficient, the higher the required optimum resonant frequency for optimum coil-to-coil efficiency and output power.
\end{abstract}

Keywords- Finite element analysis, power output, coil-to-coil efficiency, ohmic losses, eddy current losses, core losses, coil turns.

\section{INTRODUCTION}

The WPT technology based on the Magnetic Resonant coupling allows effective transfer of electrical power between two subsystems working at a particular resonant frequency[1].

In this method of wireless power transfer, the transmitter coil is receives an electrical power source, which is then transmitted to the receiver coil by means of electromagnetic resonance[1]. This technique of WPT has the benefit of transferring electrical power over a longer range when compared with the wireless power transfer technology based on the inductive approach but at a shorter range when compared with the electromagnetic radiation-based WPT approach. An added advantage also is the absence of radiation concern while transmitting high power at high transmission efficiency. The magnetic resonance coupling
WPT technology can be classified into two types: the air-core magnetic resonant coupling WPT technology and ferrite core magnetic resonant coupling WPT technology[2].

The key difference between the two categories of magnetic resonant coupling WPT technologies is the nonexistence/existence of a ferrite core in the WPT system. The air-core magnetic resonant coupling WPT system comprises of only coils of copper wire operated at very high frequencies in the megahertz range while the ferrite-core magnetic core resonant coupling WPT system comprises of a magnetic ferrite core which is used to increase the magnetic coupling and self-inductance of the resonant coils[2]-[6].For effective operation and deployment of ferrite-core magnetic resonance WPT system, there are four major performance parameters that determine the level of adaptability[18]. The performance metrics are coupling factor $(\mathrm{k})$, quality factor $(\mathrm{Q})$, power output and power transfer efficiency.

The coupling coefficient $(\mathrm{k})$ is a number that measures the ratio of the electromagnetic flux linkage between the receiver coil and the transmitter coil. Magnetically coupled coils having a $\mathrm{k} \geq 0.5$ are termed strongly or tightly coupled coils; while those coils having $\mathrm{k}$ factors $\leq 0.5$ are termed as poorly or loosely coupled coils [9]. Another important property of WPT coils is the quality factor. This is the measure of the amount of inductive properties in relation to the resistive properties of the resonant coil. It is a measure of the capacity of the coil to produce a large amount electromagnetic field which is majorly responsible for the transfer of electrical power across the airgap[9].

Similarly, the level of power transfer and efficiency of a WPT system is majorly determined by the level of losses in the systems. Typically, three types of losses is identified in the WPT system. They are ohmic losses, eddy current losses and core losses[10]-[12].

For most WPT applications, the ferrite-core magnetic resonant coupling WPT technology is the most commonly used technology used for the charging of electric vehicle because of the capability of transferring high power at high efficiency at a relatively low cost[9]. Many different WPT models have been proposed by many researchers. The common models deployed 
for practical charging of electric vehicles are the rectangular coils, circular coils, rectangular bipolar coil, and flux-pipe

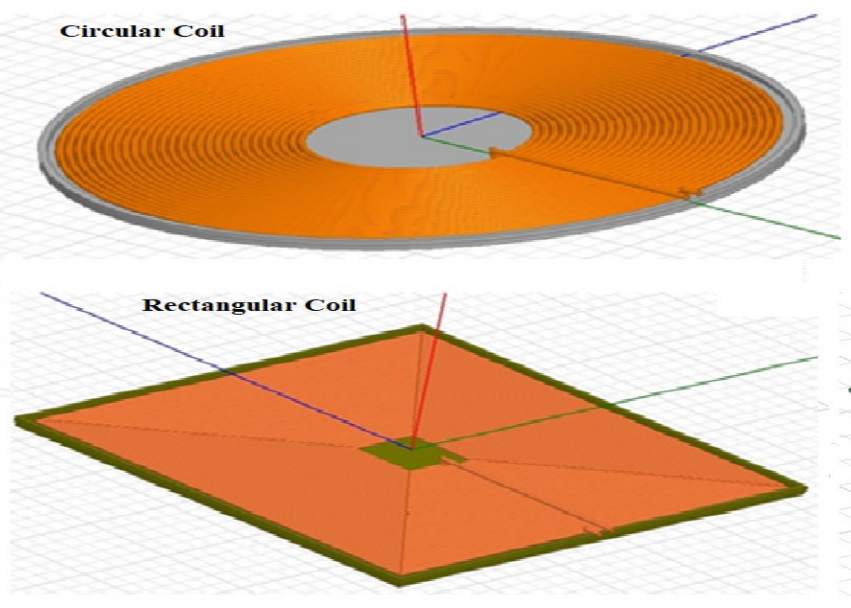

procedure gives a close approximation of the expected practical design parameters. Ansys Maxwell 3-D FEM

Figure 1. Common Geometries and Shape of Resonant Coil Design Models

coils[13]-[15]. The geometries of some of the common ferrite core coil designs are shown in Figure 1.

Each of the coil designs has their own individual performance advantages and drawbacks and have been discussed in various literature and research work[16][17]. For example, the circular coils and rectangular coils are capable of transferring a high amount of power at high efficiency but the level of power output and efficiencies decreases significantly with an increase in horizontal misalignment. In contrast, the flux-pipe coil designs have a good performance tolerance for vertical and horizontal misalignment but can only transfer low amount of electrical power at high efficiency due to the presence of double flux at the top and back sides of the flux-pipe coils. The rectangular bipolar coil was proposed to bridge the performance gap between the rectangular coil and the fluxpipe coils by providing a high power output at high transfer efficiency with relatively good horizontal misalignment tolerance. Despite the significant improvement obtained with the rectangular bipolar coil, it has a major drawback of large size and weight [18].

With respect to the flux-pipe model coils, finite element analysis has been undertaken to ascertain the impact of coil turns on the coupling factor of the coil system. In the research work of Babatunde .O. et al[19], it was noted that for a fixed length of litz wire, an increase in the number of coils turns increases the level of magnetic coupling between the primary and secondary coils.

In this research paper, a finite element modelling and analysis was employed to ascertain the impact of coil turns on the losses, power output and power transfer efficiency of fluxpipe resonant coils. Finite element modelling (FEM) approach was adopted for the design of the proposed physical coil designs because of the modelling difficulty encountered in the process of analytical modelling of resonant coils. The software tool was employed for design and analysis of the proposed design.

The performance accuracy of the proposed model designs was evaluated based on the design environment, physical modelling and boundary condition. The evaluated performance results corroborated the WPT design models of [13] and [20] with an error within a band of $\pm 6 \%$.

\section{DESIGN SPECIFICATIONS OF PROPOSED FLUX-PIPE MODELS}

\section{A. Proposed Governing Equations}

The ohmic losses (W) in the coil windings is represented mathematically by[21][22];

$P_{\text {ohmic }}=I^{2} R_{a c}$

Where $\mathrm{I}(\mathrm{A})$ is the current flowing in the coil windings and $R_{a c}(\Omega)$ is the A.C resistance of the coil windings consisting of D.C resistance and resistance due to the skin and proximity effect[21]. An optimal design must aim to reduce either the current or the total A.C resistance of the coil or both.

Likewise, the power loss (W) in the ferrite core can be expressed as[23]:

$P_{\text {core }}=C_{m} F^{\alpha} B_{\max }^{\beta}$

Where $C_{m}, \alpha$ and $\beta$ constants which are dependent on the grade and properties of the ferrite core used. For the FDK $6 \mathrm{H} 40$ ferrite core used for this research, the values of the constants are $C_{m}=2.0312, \alpha=1.418$, and $\beta=2.755[23]$. F (Hz) is the resonant frequency and $B_{\max }$ measured in Tesla $(\mathrm{T})$ is the maximum magnetic flux density in the ferrite core. Optimal design with low amount of core losses will require a design that reduces the amount of magnetic flux density as well as the resonant frequency. 
TABLE I. TABLE OF PARAMETER SPECIFICATIONS FOR FLUX-PIPE RESONANT COIL DESIGNS

\begin{tabular}{|l|l|l|l|l|l|}
\hline Parameter & Model 1 & Model 2 & Model Ref & Model 3 & Model 4 \\
\hline Width of Coils $\left(D L_{y}\right)$ & $552 \mathrm{~mm}$ & $386 \mathrm{~mm}$ & $297 \mathrm{~mm}$ & $257 \mathrm{~mm}$ & $227 \mathrm{~mm}$ \\
\hline Length of Coils $\left(D L_{x}\right)$ & $168 \mathrm{~mm}$ & $240 \mathrm{~mm}$ & $312 \mathrm{~mm}$ & $360 \mathrm{~mm}$ & $408 \mathrm{~mm}$ \\
\hline Number of Coil Turns $(\mathrm{N})$ & 14 & 20 & 26 & 30 & 34 \\
\hline Width of Ferrite Core & $538 \mathrm{~mm}$ & $372 \mathrm{~mm}$ & $283 \mathrm{~mm}$ & $243 \mathrm{~mm}$ & $213 \mathrm{~mm}$ \\
\hline Length of Ferrite Core & $203 \mathrm{~mm}$ & $293 \mathrm{~mm}$ & $385 \mathrm{~mm}$ & $448 \mathrm{~mm}$ & $511 \mathrm{~mm}$ \\
\hline Width of Aluminum Shield & $592 \mathrm{~mm}$ & $426 \mathrm{~mm}$ & $337 \mathrm{~mm}$ & $297 \mathrm{~mm}$ & $267 \mathrm{~mm}$ \\
\hline Length of Aluminum Shield & $239 \mathrm{~mm}$ & $332 \mathrm{~mm}$ & $425 \mathrm{~mm}$ & $477 \mathrm{~mm}$ & $530 \mathrm{~mm}$ \\
\hline
\end{tabular}

In the research work of P. P. Parthasaradhy and S. V Ranganayakulu [10], The power loss per unit mass of a thin sheet due to eddy current under certain conditions of uniform material and magnetic field with no skin and proximity effect is given by;

$$
P_{\theta d d y}=\frac{\pi^{2} \cdot B_{\max } \cdot d^{2} \cdot F^{2}}{6 \cdot \rho \cdot D}
$$

Where $P_{e d d y}$ is the eddy current power loss per unit mass $(\mathrm{W} / \mathrm{kg}), \mathrm{d}$ is the thickness of the shielding sheet $(\mathrm{m}), \mathrm{D}$ is the density of the material measured in $\left(\mathrm{kg} / \mathrm{m}^{3}\right)$ and $\rho$ is resistivity of the material measured in $(\Omega \mathrm{m})$. From the equation (3) given above, it can be noted that using a conductive material with higher resistivity and density reduces the amount of eddy current per unit mass in the shielding plate. Also, an increase in the magnetic flux, sheet thickness and resonant frequency increases the eddy current losses.

Similarly, Takanashi H et al [24] developed and proposed an equation relating the maximum efficiency with the quality factor and the coupling coefficient and it is given by:

$$
\begin{aligned}
\eta_{\max } & =\frac{1}{1+\frac{2}{k \sqrt{Q_{p} Q_{s}}}} \\
\eta_{\max } & =\frac{1}{1+\frac{2}{k \sqrt{Q_{p s}}}}
\end{aligned}
$$

Where $Q_{p s}$ is the product of the primary quality factor $Q_{p}$ and the secondary quality factor $Q_{s}$. Equation 5 is very useful in determining the optimum resonant frequency for a given maximum efficiency.

\section{B. Coil Design Specification of Flux-Pipe Coils}

The flux-pipe resonant coil design is modelled by winding a piece of copper wire around a ferrite bar in order to provide the shape shown in Figure 2. For a constant length of copper wire, there are many ways of generating the length and width dimension of the coil. The initial starting point is to model the core such that the length and the breadth are almost equal, and the flux-pipe model was denoted as the reference model (Ref
Model). Then the width and length are modified in order to generate different shape geometries of different length and breadth. A typical shape and dimension parameters of a fluxpipe resonant coil is shown in Table 1.

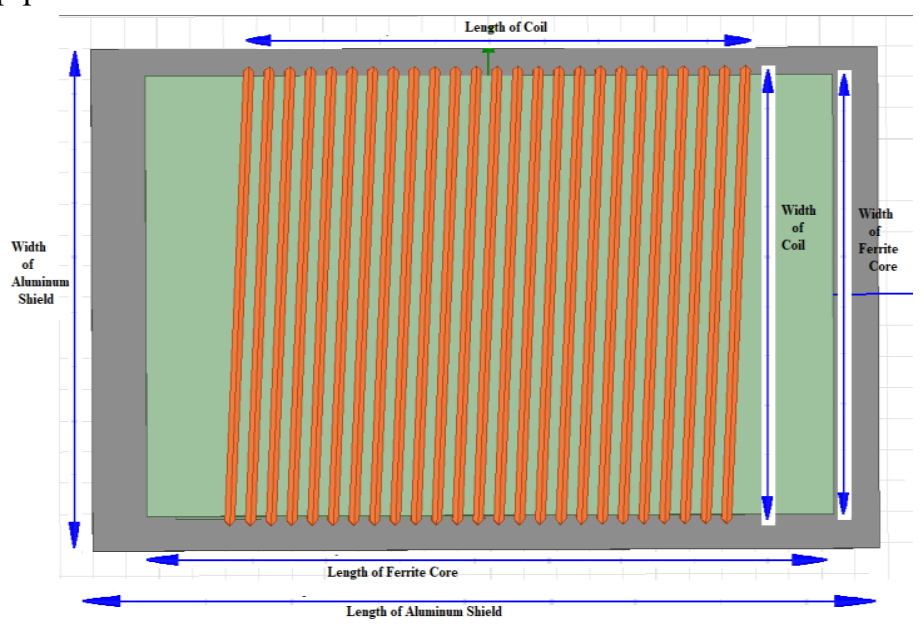

Figure 2. Dimension Parameters Specification of the Flux-Pipe Resonant Coil Model

\section{Compensation Scheme}

The compensation scheme is employed due to the presence of large magnetizing current and leakage inductance due to the large airgap.

This is achieved by applying appropriate coupling capacitance to compensate for the leakage inductance and drive the circuit into resonance. There are basically four types of compensation schemes: series-parallel, parallel-series, series-series, and parallel-parallel compensation scheme.

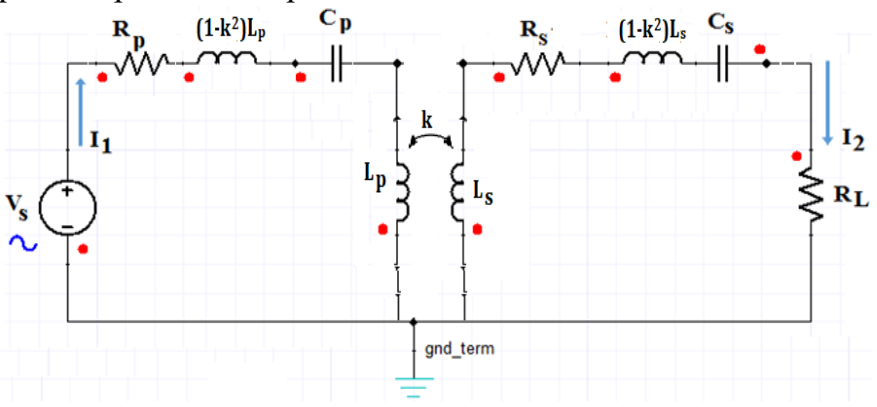

Figure 3. Equivalent Circuit for an S-S Compensation Topology 
In this paper, the series-series compensation scheme was adopted and the circuit representation is illustrated in Figure 3. The series-series combination is considered to be the most suitable for charging of electric vehicles because of the compensation ability acts as a voltage source which is immune to changes in the value of the secondary capacitance while having high power factor and transmission efficiency[2].

The value of the primary compensation capacitors $(\mathrm{Cp})$ and secondary compensation capacitors (Cs) is a function of the coupling factor $(\mathrm{k})$ and the self-inductance of the primary and secondary coils. The values of the primary and secondary compensating capacitors are given mathematically as:

$$
C_{p}=\frac{1}{\omega_{0}^{2}\left(1-k^{2}\right) L_{p}}, \quad C_{s}=\frac{1}{\omega_{0}^{2}\left(1-k^{2}\right) L_{s}}
$$

The parameter $\omega_{0}$ is the angular resonant frequency of the WPT system model measured in $\mathrm{rad} / \mathrm{s}$ and mathematically represented as $\omega_{0}=2 \pi f_{0}$, where $f_{0}$ is the resonant frequency measured in Hertz $(\mathrm{Hz})$. The term $\left(1-k^{2}\right)$ is known as the leakage factor.

\section{FINITE ELEMENT ANALYSIS OF FLUX-PIPE MODELS}

The finite analysis is undertaken to ascertain the performance of the individual coil designs based on a parametric sweep of the excitation currents and resonant frequencies in order to measure the values of the ohmic losses, eddy current losses, and the core losses.
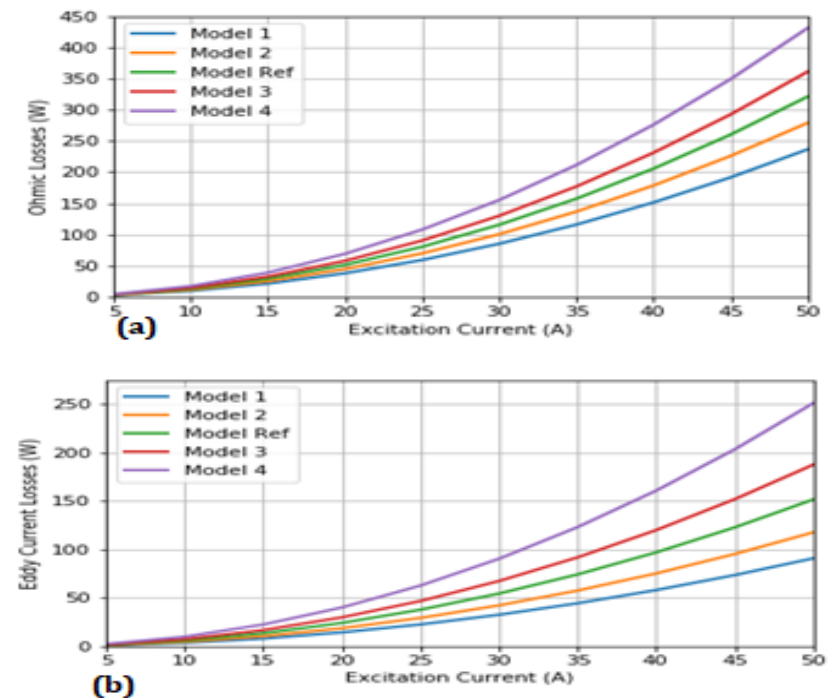

(b)

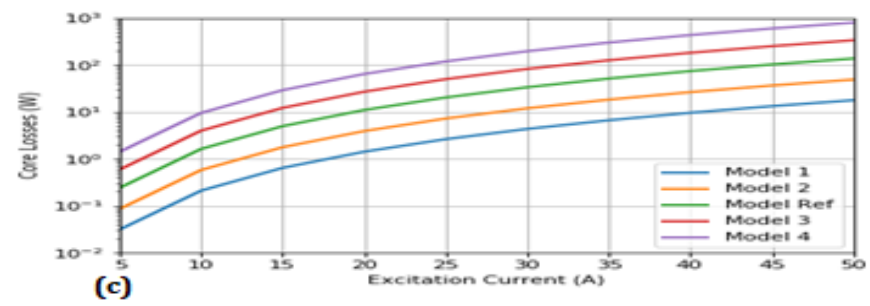

Figure 4. Losses in Flux-pipe Models due to Variation in Excitation Current. (a) Ohmic Losses. (b) Eddy Current Losses (c) Core Losses
At a particular value of electric current and frequency, the magnetic flux distribution on the ferrite cores is visualized. Similarly, the reduced order model of each model coils is imported into a circuit environment known as Ansys Simplorer ${ }^{\circledR}$ in order to obtain the optimum power output, resonant frequency and coil-to-coil efficiency of each of the flux-pipe models.

\section{A. Parametric Loss Evaluations at Constant Frequency}

The finite element analysis is undertaken by performing a parametric sweep of excitation current from $0 \mathrm{~A}$ to $50 \mathrm{~A}$ on each coil designs at a fixed frequency of $50 \mathrm{kHz}$. The result of the parametric sweep for each of the three losses is illustrated in Figure 4.

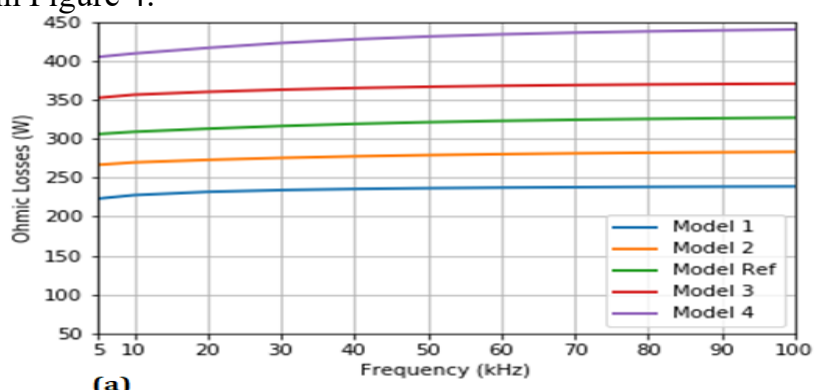

(a)

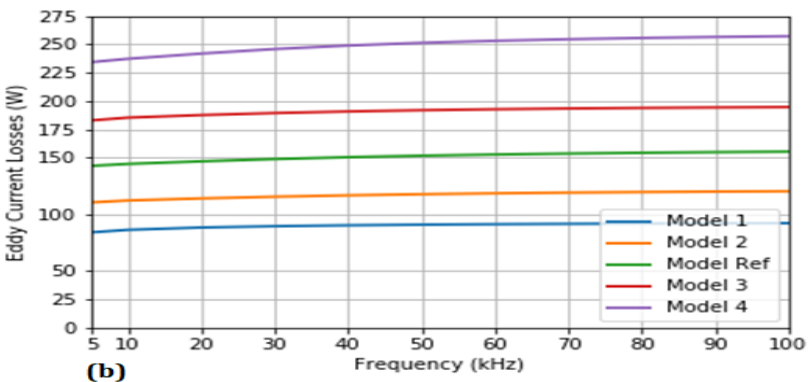

(b)

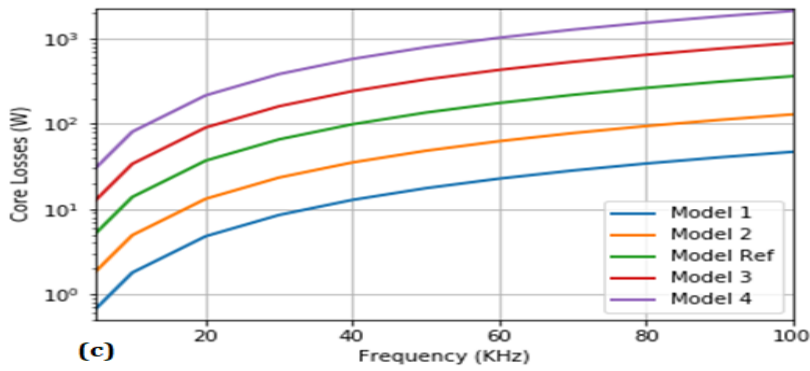

Figure 5. Losses in Flux-pipe Models due to Variation in Resonant Frequencies. (a) Ohmic Losses. (b) Eddy Current Losses (c) Core Losses

From the result shown in Figure 4 it is noted that at a constant frequency, an increase in the excitation current causes a corresponding increase in the amount of each of the three types of losses for each of the coil designs. Similarly, it is noted that for each value of the excitation current the losses increase with an increase in the number of coil turns. The increase in the amount of core and eddy current losses is as a result of increase ampere-turns which increases the value of the maximum flux density in the ferrite core. 


\section{B. Parametric Loss Evaluation at Constant Current}

The finite element analysis is undertaken by performing a parametric sweep of resonant frequencies from $5 \mathrm{kHz}$ to 100 $\mathrm{kHz}$ on each coil designs at a fixed excitation current of $50 \mathrm{~A}$. The result of the parametric sweep for each of the three losses is illustrated in Figure 5.

From the results presented in Figure 5, it is noted that at a fixed excitation current, the amount of eddy current losses and ohmic losses are relatively constant over the range of frequencies. In contrast, the amount of core losses in the WPT system increases significantly with an increase in frequencies.
From the results presented in Figure 6, it is noted that the maximum flux density increases as the number of turns increases. For example, model 1 with 14 number of turns has the least maximum flux density of $0.135 \mathrm{~T}$ while Model 4 with the highest number of turns (34 turns) has the highest maximum flux density of $0.428 \mathrm{~T}$ at the same excitation current of $50 \mathrm{~A}$. This indicates that flux-pipe with more number of coils is prone to core saturation easily than coil with less number of turns using an equivalent length of copper wire.
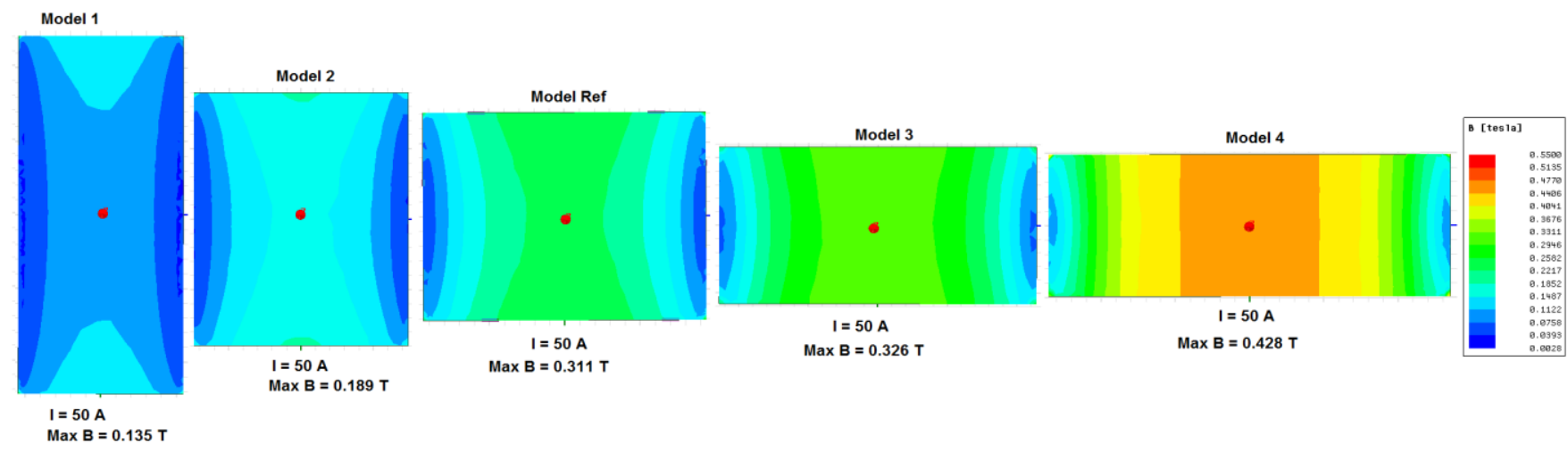

Figure 6. Magnetic Flux Distribution in Ferrite Cores for Flux-Pipe Resonant Coils

Thus, the value of the resonant frequency has little impact on the amount of ohmic losses and eddy current losses in the system. Similarly, at each of the resonant frequencies, the losses increase with an increase in the number of coil turns.

\section{EFFICIENCY EVALUATIONS OF FLUX-PIPE MODELS}

In order to ascertain the individual performance of each of the flux-pipe model coil designs in terms of optimum coil-to-coil efficiency, power output, and total power losses, the evaluated

TABLE II. SUMMARY OF PERFORMANCE CHARACTERISTICS OF FLUX-PIPE OIL MODELS FOR S-S CONFIGURATION

\begin{tabular}{|l|c|c|c|c|c|}
\hline \multirow{2}{*}{ Parameters } & \multicolumn{3}{|c|}{ S-S Configuration } \\
\cline { 2 - 6 } & Model 1 & Model 2 & Model Ref & Model 3 & Model 4 \\
\hline Resonant Frequency & $130 \mathrm{kHz}$ & $100 \mathrm{kHz}$ & $60 \mathrm{kHz}$ & $40 \mathrm{kHz}$ & $30 \mathrm{kHz}$ \\
\hline $\mathrm{k} \sqrt{ } \mathrm{Q}_{\mathrm{ps}}$ & 341 & 333 & 318 & 310 & 309 \\
\hline Input Voltage & $300 \mathrm{~V}$ & $300 \mathrm{~V}$ & $300 \mathrm{~V}$ & $298 \mathrm{~V}$ & $285 \mathrm{~V}$ \\
\hline Output Voltage & $340 \mathrm{~V}$ & $330 \mathrm{~V}$ & $302 \mathrm{~V}$ & $200 \mathrm{~V}$ & $20 \Omega$ \\
\hline Load Resistance & $20 \Omega$ & $20 \Omega$ & $20 \Omega$ & $15.13 \mathrm{~A}$ & $13.81 \mathrm{~A}$ \\
\hline Input Current & $19.72 \mathrm{~A}$ & $18.48 \mathrm{~A}$ & $15.48 \mathrm{~A}$ & $14.92 \mathrm{~A}$ & $14.25 \mathrm{~A}$ \\
\hline Output Current & $17.02 \mathrm{~A}$ & $16.48 \mathrm{~A}$ & $15.09 \mathrm{~A}$ & $4.54 \mathrm{~kW}$ & $4.14 \mathrm{~kW}$ \\
\hline Input Power & $5.90 \mathrm{~kW}$ & $5.54 \mathrm{~kW}$ & $4.64 \mathrm{~kW}$ & $4.45 \mathrm{~kW}$ & $4.06 \mathrm{~kW}$ \\
\hline Output Power & $5.79 \mathrm{~kW}$ & $5.43 \mathrm{~kW}$ & $4.56 \mathrm{~kW}$ & $90 \mathrm{~W}$ & $80 \mathrm{~W}$ \\
\hline Total Power Losses & $110 \mathrm{~W}$ & $110 \mathrm{~W}$ & $80 \mathrm{~W}$ & $98.05 \%$ & $98.02 \%$ \\
\hline Coil-to-Coil Efficiency & $98.10 \%$ & $98.05 \%$ & $98.09 \%$ & & $2 \%$ \\
\hline
\end{tabular}

\section{Magnetic Flux Distribution Analysis}

At an excitation current of 50A, a magnetostatic analysis was performed on each of the five flux-pipe model designs. The magnetic flux distribution in the ferrite core of each model is illustrated in Figure 6. model solution from the finite element analysis at constant current is imported into the circuit analysis environment called Ansys Simplorer and the desired results evaluated. The evaluated results for each of the flux pipe model designs at a minimum coil-to-coil efficiency of $98 \%$ is shown in Table II. 
From the result presented in Table II, it is noted that the mathematical term $\mathrm{k} \sqrt{ } \mathrm{Q}_{\mathrm{ps}}$ has a significant impact on the power output, power input, and coil-to-coil efficiency of a particular flux-pipe resonant coil design. For example, Model 1 with the highest value of $k \sqrt{ } Q_{p s}$ has the highest values of output power and coil-to-coil efficiency while Model 4 with the minimum value of $k \sqrt{ } Q_{p s}$ has the minimum value of power output and coil-to-coil efficiency. Similarly, the lower the number of coil turns, the higher the required optimum resonant frequency for optimum power output and coil-to-coil efficiency.

For optimum design specifications, there is a required tradeoff between resonant frequency and power output for any particular application.

\section{CONCLUSION}

This paper presents a finite element analysis of five different flux-pipe resonant coil design with a different number of coils turns but having the same length of litz copper wire. The analysis was undertaken to ascertain the impact of coil turns on the losses, magnetic flux distribution, power output, and power transfer efficiency of flux-pipe resonant coils.

From the result presented, it was noted at a constant frequency, an increase in the excitation current causes a significant increase in the ohmic, core, and eddy current losses for each of the coil model designs. Similarly, at constant excitation current, it was observed that the eddy current losses increase significantly with an increase in resonant frequency. In contrast, the ohmic and core losses are relatively constant over the range of resonant frequencies used in the analysis. It was also noted that term $\mathrm{k} \vee \mathrm{Q}_{\mathrm{ps}}$ has a significant impact on the input power, output power and coil-to-coil efficiency of a particular flux-pipe resonant coil design. Increasing the value of $k \sqrt{ } Q_{p s}$ increases the value of power input, power output and coil-to-coil efficiency. Similarly, the lower the number of coil turns, the higher the required optimum resonant frequency for optimum output power and coil-to-coil efficiency.

For optimum design specifications, there is a required tradeoff between resonant frequency and power output for a particular application.

\section{REFERENCES}

[1] O. Jonah and S. V. Georgakopoulos, "Wireless power transfer in concrete via strongly coupled magnetic resonance," IEEE Trans. Antennas Propag., vol. 61, no. 3, pp. 1378-1384, 2013.

[2] K. A. Kalwar, M. Aamir, and S. Mekhilef, "Inductively coupled power transfer (ICPT) for electric vehicle charging - A review," Renew. Sustain. Energy Rev., vol. 47, pp. 462-475, 2015.

[3] X. Mou and H. Sun, "Wireless power transfer: Survey and roadmap," in IEEE Vehicular Technology Conference, 2015, vol. 2015, pp. 1-5.

[4] K. Fotopoulou and B. W. Flynn, "Wireless power transfer in loosely coupled links: Coil misalignment model," IEEE Trans. Magn., vol. 47, no. 2 PART 2, pp. 416-430, 2011.

[5] Z. Tang, M. Christini, T. Koga, and ANSYS, "Wireless Power Transfer using Maxwell and Simplorer," 2012 Automot. Simul. World Congr., pp. 1-38, 2012.

[6] M. Budhia, G. A. Covic, and J. T. Boys, "Design and optimisation of magnetic structures for lumped inductive power transfer systems," 2009 IEEE Energy Convers. Congr. Expo. ECCE 2009, pp. 2081-2088, 2009.

[7] J. Donadee, M. Ilić, and O. Karabasoglu, "Optimal autonomous charging of electric vehicles with stochastic driver behavior," 2014 IEEE Veh. Power Propuls. Conf. VPPC 2014, 2015.

[8] D. Kürschner, C. Rathge, and U. Jumar, "Design methodology for high efficient inductive power transfer systems with high coil positioning flexibility," IEEE Trans. Ind. Electron., vol. 60, no. 1, pp. 372-381, 2013.

[9] K. A. Kalwar, M. Aamir, and S. Mekhilef, "Inductively coupled power transfer (ICPT) for electric vehicle charging - A review," Renew. Sustain. Energy Rev., vol. 47, pp. 462-475, 2015.

[10] P. P. Parthasaradhy and S. V Ranganayakulu, "Hysteresis and eddy current losses of magnetic material by Epstein frame method-novel approach," Int. Conf. Innov. Electr. Electron. Eng., pp. 85-93, 2014.

[11] D. Chen, L. Wang, C. Liao, and Y. Guo, "The power loss analysis for resonant wireless power transfer," IEEE Transp. Electrif. Conf. Expo, ITEC Asia-Pacific 2014 - Conf. Proc., pp. 1-4, 2014.

[12] D. Barth, B. Klaus, and T. Leibfried, "Litz wire design for wireless power transfer in electric vehicles," in WPTC 2017 - Wireless Power Transfer Conference, 2017.

[13] G. Lempidis, "Wired and wire less charging of electri ic vehicles," pp. 1-7, 2014.

[14] M. Chigira, Y. Nagatsuka, Y. Kaneko, S. Abe, T. Yasuda, and A. Suzuki, "Small-size light-weight transformer with new core structure for contactless electric vehicle power transfer system," IEEE Energy Convers. Congr. Expo. Energy Convers. Innov. a Clean Energy Futur. ECCE 2011, Proc., pp. 260-266, 2011.

[15] Y. Nagatsuka, N. Ehara, Y. Kaneko, S. Abe, and T. Yasuda, "Compact contactless power transfer system for electric vehicles," 2010 Int. Power Electron. Conf. - ECCE Asia -, IPEC 2010, pp. 807-813, 2010.

[16] C. Panchal, S. Stegen, and J. Lu, "Review of static and dynamic wireless electric vehicle charging system," Engineering Science and Technology, an International Journal, vol. 21, no. 5. pp. 922-937, 2018.

[17] E. G. Kilinc, C. Dehollain, and F. Maloberti, "Design and optimization of inductive power transmission for implantable sensor system," 2010 11th Int. Work. Symb. Numer. Methods, Model. Appl. to Circuit Des. SM2ACD 2010, no. 1, pp. 10-14, 2010.

[18] T. D. Nguyen, S. Li, W. Li, and C. C. Mi, "Feasibility study on bipolar pads for efficient wireless power chargers," Conf. Proc. IEEE Appl. Power Electron. Conf. Expo. - APEC, pp. 1676-1682, 2014.

[19] B. Olukotun, J. S. Partridge, and R. W. G. Bucknall, "Optimal Finite Element Modelling and 3-D Parametric Analysis of Strong Coupled Resonant Coils for Bidirectional Wireless Power Transfer," Proc. - 2018 53rd Int. Univ. Power Eng. Conf. UPEC 2018, pp. 1-6, 2018

[20] K. Throngnumchai, A. Hanamura, Y. Naruse, and K. Takeda, "Design and evaluation of a wireless power transfer system with road embedded transmitter coils for dynamic charging of electric vehicles," World Electr. Veh. J., vol. 6, no. 4, pp. 848-857, 2013.

[21] S. Sotiriou, "Analysis of Operation and System Losses of an Inductive Power Transfer System for Wireless Charging of Electric Vehicles," no. September, 2014.

[22] K. Jaber, B. Ben Saleh, A. Fakhfakh, and R. Neji, "Modeling and simulation of electrical vehicle in VHDL-AMS," 2009 16th IEEE Int. Conf. Electron. Circuits Syst. ICECS 2009, pp. 908-911, 2009.

[23] M. Mohammad, S. Kwak, and S. Choi, "Core design for better misalignment tolerance and higher range of wireless charging for HEV," Conf. Proc. - IEEE Appl. Power Electron. Conf. Expo. APEC, vol. 2016-May, no. 2, pp. 1748-1755, 2016.

[24] H. Takanashi, Y. Sato, Y. Kaneko, S. Abe, and T. Yasuda, "A large air gap $3 \mathrm{~kW}$ wireless power transfer system for electric vehicles," 2012 IEEE Energy Convers. Congr. Expo. ECCE 2012, pp. 269$274,2012$. 